\title{
Retroperitonealni limfangiom kao uzrok akutnog abdomena - prikaz slučaja
}

\section{Retroperitoneal lymphangioma presenting as acute abdomen: A case report}

\author{
Katja Gavrić ${ }^{1}$, Mirko Balić ${ }^{2}$, Harry Nikolić ${ }^{3}$, Koviljka Matušan Ilijaš ${ }^{4}$, Jelena Roganovićs*
}

\begin{abstract}
Sažetak. Cilj: Prikazati pedijatrijskog pacijenta s retroperitonealnim limfangiomom koji se prezentirao kao akutni abdomen. Prikaz slučaja: Dvanaestogodišnji dječak hospitaliziran je zbog akutnih grčevitih bolova u trbuhu praćenih povraćanjem i povišenim laboratorijskim upalnim parametrima. Zbog sumnje na akutni apendicitis učinjena je hitna klasična apendektomija. Drugog postoperativnog dana nastupilo je pogoršanje općeg stanja $s$ febrilitetom i difuznim abdominalnim bolovima. Slikovnim pretragama abdomena prikazana je pseudocistična septirana tvorba koja je sugerirala limfangiom. Po provedenoj energičnoj potpornoj terapiji i poboljšanju općeg stanja učinjena je kompletna kirurška resekcija tumora. Postoperativni tijek protekao je uredno. Patohistološki nalaz potvrdio je dijagnozu limfangioma. Šest mjeseci nakon operativnog zahvata dječak je bez tegoba s urednim kliničkim i ultrazvučnim nalazom. Zaključak: Akutni abdomen je hitno kirurško stanje vrlo različite etiologije koje, posebice u djece, zahtijeva pažljiv pristup. U diferencijalnoj dijagnozi akutnog abdomena treba razmišljati i o limfangiomu. Detaljna anamneza, pažljiv klinički pregled, radiološka i laboratorijska obrada značajno utječu na izbor terapije i prognozu bolesti.
\end{abstract}

Ključne riječi: akutni abdomen; apendektomija; limfangiom

\begin{abstract}
Aim: To report a case of a pediatric patient with acute abdomen due to a retroperitoneal lymphangioma. Case report: A 12-year old boy was admitted to the hospital due to acute spasmodic abdominal pain, accompanied by vomiting and raised inflammatory markers. A classical appendectomy was performed due to clinical suspicion of appendicitis. On the second post-operative day, the general condition deteriorated, with fever and diffuse abdominal pain. Abdominal imaging studies demonstrated a pseudocystic septic formation suggestive of lymphangioma. Following extensive supportive therapy and improvement of general condition, the tumor was completely surgically resected. The postoperative course was uneventful. Histopathological examination confirmed the diagnosis of lymphangioma. Six months after the surgery, the boy is doing well and his clinical and ultrasound follow-up examinations are normal. Conclusion: Acute abdomen is a surgical emergency with many possible causes, which requires a careful approach regarding the specifics of the pediatric population. Whilst creating a differential diagnosis, lymphangioma should be considered. Detailed history, careful physical examination and radiological investigations are of great impact on the choice of treatment and the prognosis of the disease.
\end{abstract}

Key words: acute abdomen; appendectomy; lymphangioma

Napomena: Prikaz slučaja izrađen je u sklopu radionice „Kako napisati dobar prikaz slučaja?“, u organizaciji časopisa Medicina Fluminensis Medicinskog fakulteta Sveučilišta u Rijeci i Znanstvenog odbora svih studenata (ZOSS) Medicinskog fakulteta Sveučilišta u Rijeci (voditeljica: doc. dr. sc. Nina Pereza, dr. med.).

\author{
${ }^{1}$ Medicinski fakultet Sveučilišta u Rijeci, \\ Rijeka \\ ${ }^{2}$ Klinika za radiologiju, Klinički bolnički \\ centar Rijeka, Rijeka \\ ${ }^{3}$ Klinika za dječju kirurgiju, Klinički bolnički \\ centar Rijeka, Rijeka \\ ${ }^{4}$ Zavod za patologiju, Klinički bolnički \\ centar Rijeka, Rijeka \\ ${ }^{5}$ Klinika za pedijatriju, Klinički bolnički \\ centar Rijeka, Rijeka
}




\section{UVOD}

Limfangiom je rijetka benigna malformacija limfnih žila s učestalošću od 1 : 2000 do 4000 živorođene djece. Najčešće lokalizacije su područja vrata i aksile (54 \% slučajeva). Abdominalna lokalizacija prisutna je u $7 \%$ pacijenata, a retroperitoneum je zahvaćen vrlo rijetko ${ }^{1,2}$.

Klinička prezentacija abdominalnih limfangioma prvenstveno ovisi o veličini i lokalizaciji tvorbe, s varijacijom od asimptomatske do akutnog abdomena ${ }^{3}$.

Limfangiom je rijetka benigna malformacija limfnih žila najčešće prisutna u području vrata i aksile. Klinička prezentacija osobito rijetkih, abdominalnih limfangioma, prvenstveno ovisi o veličini i lokalizaciji tvorbe, s varijacijom od asimptomatske do akutnog abdomena.

Najčešći simptomi i znakovi su abdominalni bolovi, distenzija abdomena, palpabilna tvorba, mučnina, povraćanje, konstipacija i dijareja ${ }^{3-5}$. Akutni abdomen rezultat je infekcije ili krvarenja unutar cisti, torzije ili rupture tumora, kompresije okolnih struktura, volvulusa i intestinalne opstrukcije ${ }^{6}$.

Akutni abdomen u djece školske dobi najčešće je uzrokovan apendicitisom ${ }^{7}$. Odluka o potrebi detaljnije dijagnostičke obrade djeteta s akutnim abdomenom predstavlja izazov za kliničara, a od izuzetne su važnosti detaljna anamneza i pažljiv fizikalni pregled ${ }^{8}$.

$\mathrm{U}$ radu je prikazan pedijatrijski pacijent s retroperitonealnim limfangiomom koji se prezentirao slikom akutnog abdomena.

\section{PRIKAZ SLUČAJA}

Dvanaestogodišnji dječak hospitaliziran je u Klinici za dječju kirurgiju Kliničkog bolničkog centra Rijeka zbog akutnih grčevitih abdominalnih bolova praćenih povraćanjem. Prilikom prijama bio je blaže poremećenog općeg stanja, s palpatornom bolnošću ileocekalne regije. Laboratorijske pretrage krvi pokazale su leukocitozu s neutrofilijom [L (leukociti) $33.9 \times 10^{9} / \mathrm{L}$, referentne vrijednosti: $4.4-11.6 \times 10^{9} / \mathrm{L}, \mathrm{Neu}$ (neutrofilni granulociti) $29.7 \times 10^{9} / \mathrm{L}, 87.5$ rel \%, referentne vrijednosti: $\left.\left.1.49-8.00 \times 10^{9} / \mathrm{L}, 34-69 \%\right)\right]$ i povišen C-reaktivni protein (CRP $34.2 \mathrm{mg} / \mathrm{L}$, referentne vrijednosti: $0.1-2.8 \mathrm{mg} / \mathrm{L})$.

Zbog sumnje na akutni apendicitis učinjena je hitna klasična apendektomija. Prema mišljenju kirurga crvuljak je bio flegmonozno promijenjen, a uzorak je upućen na patohistološku analizu. Drugog postoperativnog dana dječak je bio lošijeg općeg stanja i ponovno se žalio na difuzne bolove u abdomenu, a vrijednosti CRP-a bile su u porastu (132.5 mg/L).

Upućen je na ultrazvuk abdomena na kojem je prikazana dobro ograničena, pseudocistična septirana formacija veličine cca. $13 \times 12 \mathrm{~cm}$, lokalizirana u desnom hemiabdomenu od područja donjeg pola desnog bubrega do zdjelice. Nalaz je sugerirao mezenterijalni limfangiom. Kompjutorizirana tomografija abdomena i zdjelice (engl. computed tomography, CT) potvrdila je ultrazvučni nalaz (slika 1).

Konzultiran je infektolog, koji je zbog sumnje na gangrenozni apendicitis preporučio kombiniranu
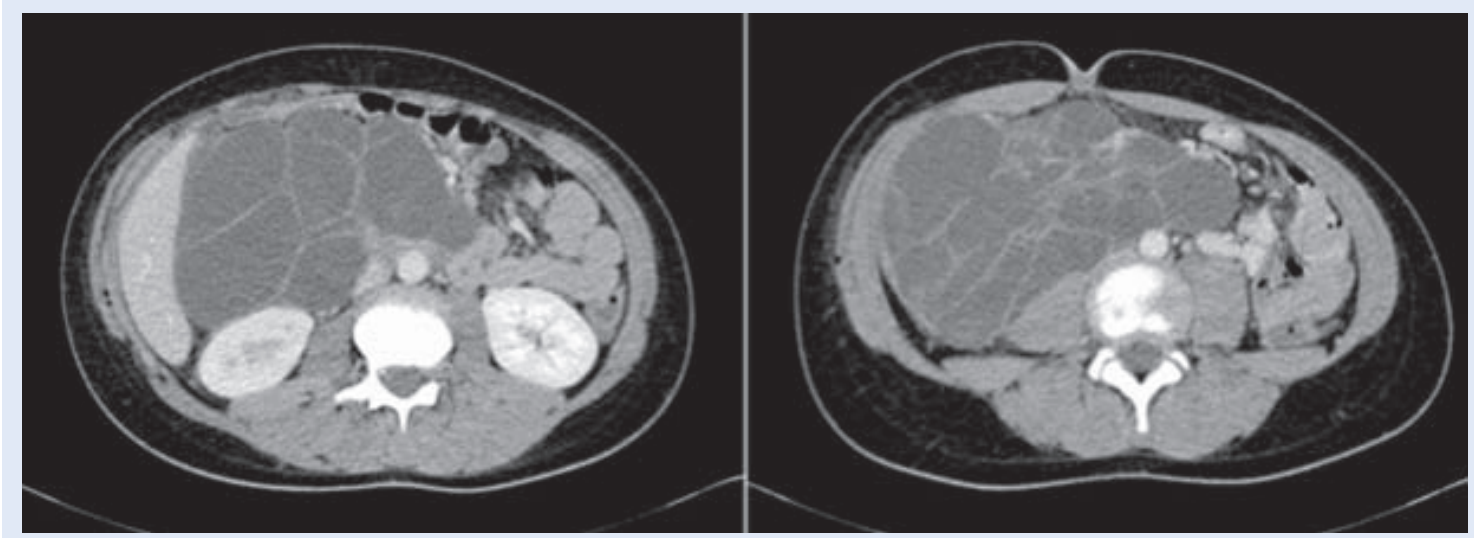

Slika 1. Kompjutorizirana tomografija abdomena i zdjelice. Dobro ograničena, pseudocistična, septirana, većim dijelom hipodenzna formacija pretežno u desnom hemiabdomenu koja komprimira okolne mekotkivne i vaskularne strukture. 


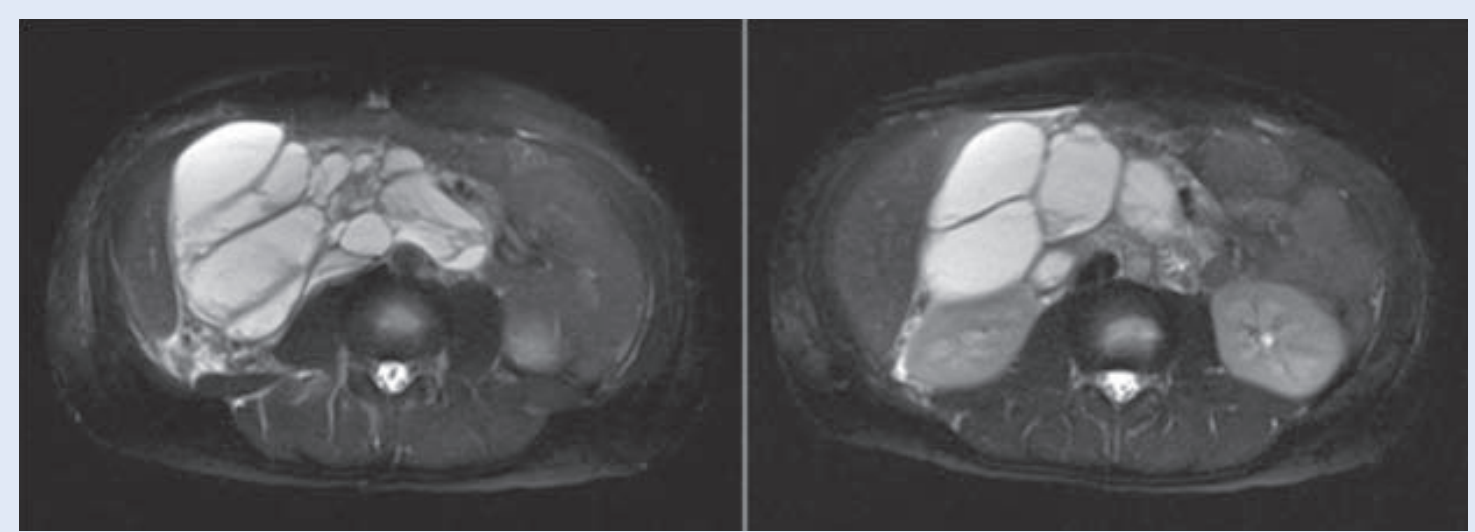

Slika 2. Magnetska rezonancija abdomena, T2-mjerena snimka. Opsežna, dominantno multicistična lezija, uglavnom $s$ desne strane, koja široko priliježe uz psoas i uzrokuje djelomičnu blokadu desnog bubrega s hidronefrozom prvog stupnja. Ne infiltrira okolinu, ali zbog svoje ekstenzivnosti potiskuje crijevne vijuge prema naprijed i lijevo. Vidljivi su znaci hemoragije unutar pojedinih cističnih tvorbi. Nalaz upućuje na retroperitonealni limfangiom.

parenteralnu antibiotsku terapiju (ceftriakson i metronidazol). Dječak je svakodnevno bio febrilan do $38.3^{\circ} \mathrm{C}$ i dalje se povremeno žalio na bolove $\mathrm{u}$ trbuhu. Hemokulture su bile negativne, a upalni laboratorijski parametri u blagom padu ( $L 23.7 \mathrm{x}$ 10\% / L, CRP $85.5 \mathrm{mg} / \mathrm{L})$. U daljnjem tijeku bio je hipokalemičan (Kalij $3.2 \mathrm{mmol} / \mathrm{L}$, referentne vrijednosti: 3.6 - $5.0 \mathrm{mmol} / \mathrm{L})$. Povišene vrijednosti serumske lipaze te amilaze u serumu i urinu upućivale su na akutni pankreatitis. Testovima koagulacije verificirano je produljeno protrombinsko vrijeme (0.47, referentne vrijednosti: $0.70-1.40$ ). $S$ obzirom na pogoršanje općeg stanja s intenziviranjem bolova i povraćanjem konzultiran je dječji hematolog radi potporne terapije te je pacijent dogovorno premješten na Odjel za hematologiju i onkologiju Klinike za pedijatriju.

Revidirana je antibiotska terapija (tigeciklin, cefepim), uvedena antiemetska i antifungalna terapija (flukonazol), potpuna parenteralna prehrana, tromboprofilaksa, gastroprofilaksa te korekcija hipoalbuminemije i hipokalemije. U ponovljenom koagulogramu perzistiralo je produljeno protrombinsko vrijeme (0.53), a specifični testovi zgrušavanja verificirali su snižene vrijednosti Faktora VII (33 \%). U daljnjem tijeku nastupilo je značajno kliničko i laboratorijsko poboljšanje ( $8.8 \mathrm{x}$ 10\%/L, CRP $6.4 \mathrm{mg} / \mathrm{L}, \mathrm{K} 4.4 \mathrm{mmol} / \mathrm{L}$, protrombinsko vrijeme 0.71). Prema naknadno dobivenim anamnestičkim podacima od majke dječak se unatrag više godina povremeno žalio na neodređene bolove u gornjem abdomenu. Patohistološki nalaz opisao je crvuljak bez upalnih promjena.
Magnetska rezonancija abdomena (engl. magnetic resonance imaging, MRI) pružila je detaljan uvid u izgled i lokalizaciju tvorbe te odnos s okolnim strukturama. Prikazana je opsežna multicistična lezija bez znakova infiltracije okoline, lokalizirana pretežno u desnom hemiabdomenu, od dvanaesnika i glave gušterače do zdjelice. Topoanatomska lokalizacija lezije bila je prvenstveno retroperitonealna, no s obzirom na veličinu izbočila se aneteriorno između crijevnih vijuga koje je potiskivala prema naprijed i ulijevo. Lezija je široko prilijegala uz desni mišić psoas, a posljedično i na desni ureter. Bila je prisutna djelomična blokada desnog bubrega s hidronefrozom prvog stupnja. Unutar pojedinih cističnih tvorbi bio je vidljiv hemoragični sadržaj. MR nalaz bio je tipičan za retroperitonealni limfangiom (slika 2). Pacijent je prikazan na Konziliju (dječji hematolog, dječji kirurg, abdominalni kirurg, radiolog) koji je indicirao kirurško liječenje. Podvrgnut je operativnom zahvatu s kompletnom resekcijom tumora. Postoperativni tijek je, uz intenzivnu potpornu terapiju (parenteralna hidracija, gastroprofilaksa, tromboprofilaksa, antiemetska terapija, vitamin K), protekao uredno.

Patohistološki nalaz potvrdio je dijagnozu limfangioma. Opisana je tvorba građena od veziva s nešto masnog tkiva, s brojnim vaskularnim prostorima nepravilnih lumena obloženih pravilnim endotelom. Većina vaskularnih prostora bila je prazna, dok je u ponekim bilo nakupina limfocita, blijedo ružičaste tekućine, fibrina i eritrocita. Stijenke tvorbe bile su građene od snopića glatke muskula- 


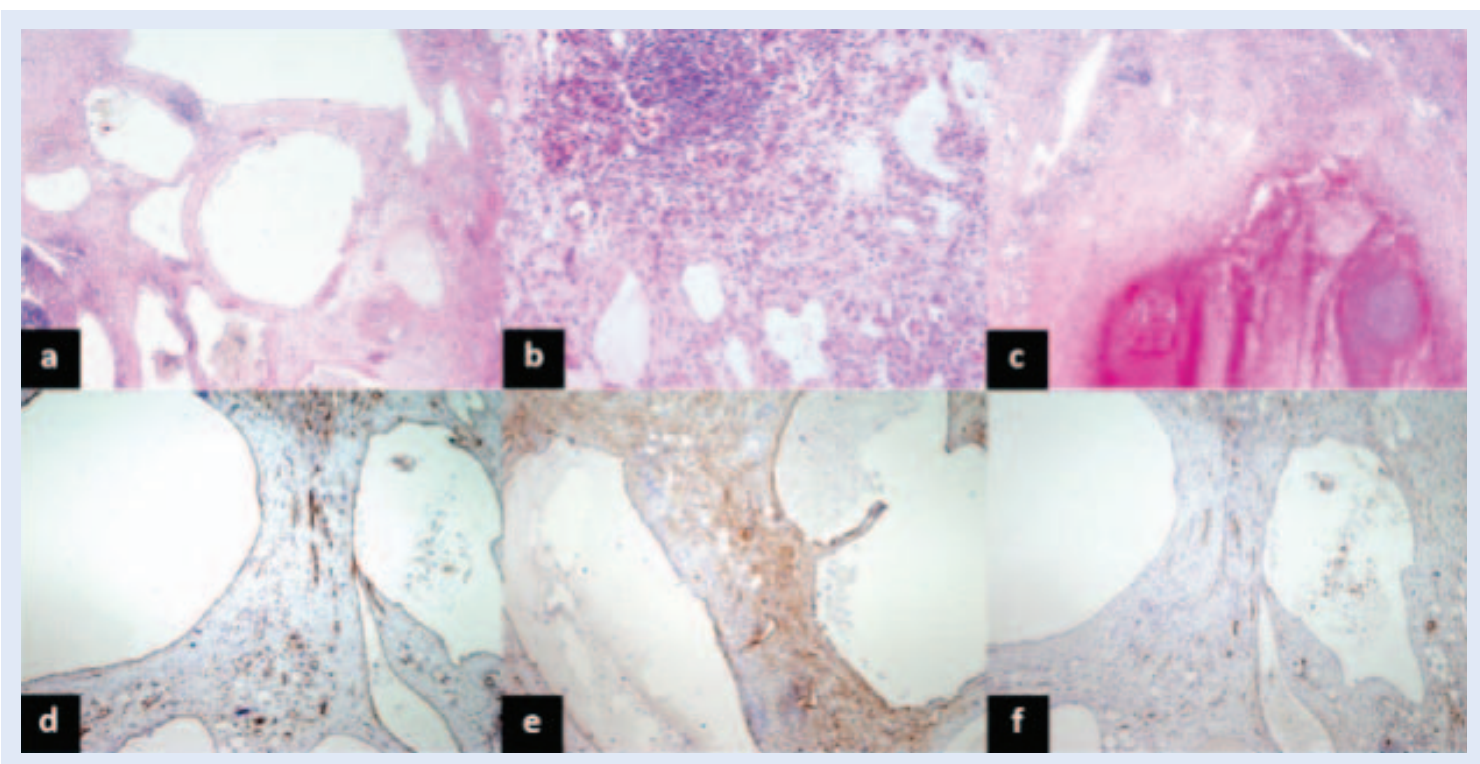

Slika 3. Patohistološka analiza retroperitonealne multicistične lezije. Lezija je smještena unutar retroperitonealnog masnog tkiva i građena je od različito velikih vaskularnih prostora nepravilnih, većinom praznih lumena, koji su obloženi pravilnim endotelnim stanicama, a okruženi su mjestimice snopićima glatkih mišićnih stanica (a). U okolici se nalaze fokusi limfocita (b) te područja likvefakcijske i hemoragične nekroze okružena granulacijskim tkivom (c). Bojanje hemalaun-eozin, povećanje $\times 2$ (a, c), $\times 10$ (b). Imunohistokemijska analiza prikazuje leziju podrijetla endotelnih stanica limfnih žila: CD31 biljeg boji smeđe endotelne stanice vaskularnih prostora lezije (d) kao i D2-40 biljeg (e). WT-1 biljeg boji smeđe citoplazme endotelnih stanica krvnih žila kao i citoplazme nekih upalnih stanica (f), ali ne i vaskularne prostore opisane lezije, što upućuje da se radi o malformaciji podrijetla endotela limfnih žila. Imunohistokemijsko DAB bojenje kontrastirano hematoksilinom, povećanje $\times 4(d, e, f)$.

ture i edematoznog veziva s umnoženim kapilarama i fokusima limfocita. Mjestimično su se vidjela opsežna područja likvefakcijske i hemoragične nekroze okružena granulacijskim tkivom (slika 3).

Dječak je otpušten kući nakon dva tjedna. U daljnjem tijeku redovito je ambulantno kontroliran. Šest mjeseci nakon operativnog zahvata je bez tegoba, s urednim kliničkim, laboratorijskim i ultrazvučnim nalazima.

\section{RASPRAVA}

Limfangiom opisan ovim prikazom slučaja rijetka je benigna kongenitalna limfatička malformacija nedovoljno razjašnjene etiologije. Najzastupljenija embriološka teorija objašnjava nastanak limfangioma sekvestracijom limfatičnog tkiva tijekom razvoja limfatičko-venskih vrećica. Dilatacija limfatičnog tkiva rezultira cističnim izgledom lezije ${ }^{1,10}$.

Oko $50 \%$ limfangioma prisutno je pri rođenju, a gotovo $90 \%$ se dijagnosticira do 2 . godine života ${ }^{11}$. Pretežno se nalaze u području vrata i aksile ${ }^{1}$. Intraabdominalni limfangiom je rijedak, a retroperitoneum je najrjeđa abdominalna lokalizacija ${ }^{1-2}$.
Klinička slika intraabdominalnih limfangioma varira od asimptomatskih oblika, preko slučajno otkrivene bolesti tijekom obrade neodređene abdominalnog bola, do hitnog kirurškog stanja. U otprilike polovine pacijenata prisutan je bol u trbuhu ${ }^{3-5,9}$. Druge moguće tegobe su mučnina, povraćanje, distenzija ili papabilna tvorba u trbuhu, konstipacija i dijareja ${ }^{3-5,12}$. Komplikacije, uključujući akutni abdomen, posljedica su infekcije ili intratumorskog krvarenja, intestinalne opstrukcije, volvulusa ili traumatske rupture ${ }^{6}$.

Podrobna anamneza i fizikalni pregled ključni su u odabiru slikovne metode za optimalnu vizualizaciju tvorbe. Radiogram abdomena ne pruža dovoljno informacija, stoga se ne preporučuje ${ }^{13}$. Ultrazvučna pretraga često je prva slikovna metoda izbora, a korisna je i za postoperativno praće$n \mathrm{e}^{5,13}$. MR i CT bolje prikazuju karakteristike tvorbe i odnos prema susjednim strukturama te daju vrijedne podatke u preoperativnoj pripremi pacijenata. Mjerenjem gustoće ili intenziteta signala tekućine u cistama može se zaključiti je li sadržaj serozan, hilozan ili sangvinozan ${ }^{12-13}$. 
Diferencijalno-dijagnostički u obzir dolaze druge intraabdominalne cistične tvorbe poput enteričke i enteričke duplikacijske ciste, mezotelne ciste, pseudociste pankreasa ili neoplazme poput mezotelioma, lipoma, teratoma, leiomiosarkoma ili liposarkoma ${ }^{15}$. Stoga je jedina pretraga koja može pouzdano potvrditi dijagnozu patohistološka analiza tumorskog tkiva ${ }^{11,16}$.

$U$ našeg pacijenta limfangiom je dijagnosticiran $u$ dobi od 12 godina, što je puno kasnije od srednje dobi kod postavljanja dijagnoze limfangioma ${ }^{11}$. Detaljnom anamnezom dobiveni su podaci o višegodišnjim neodređenim bolovima, pretežno u gornjem abdomenu, koji nisu zahtijevali liječničku pozornost. Cistični limfangiomi rijetko se prezentiraju kao intraabdominalne tvorbe, a posebice je rijetka retroperitonealna lokalizaci$j^{1,2}$. Također je vrlo rijetka prezentacija limfangioma hitnim kirurškim stanjem ${ }^{3,5-6,17}$.

Akutni abdomen u našeg pacijenta najvjerojatnije je posljedica intratumorskog krvarenja i infekcije, koji su dokazani patohistološkim pregledom tvorbe s opsežnim područjima likvefakcijske i hemoragične nekroze okružene granulacijskim tkivom. Bolovi također mogu biti uzrokovani kompresijom susjednih struktura zbog veličine tvorbe, posebice mišića psoasa, crijeva i bubrega. Abdominalni bolovi i distenzija abdomena u prikazanom slučaju u hitnoj službi protumačeni su akutnom upalom crvuljka te je učinjena apendektomija.

lako je apendicitis najčešći razlog abdominalnog bola koji zahtijeva kiruršku intervenciju u djece školske dobi, u pacijenata u kojih izostaju klasični simptomi i znakovi treba bez odgađanja učiniti slikovne pretrage ${ }^{7-8}$. U našeg pacijenta ultrazvučna pretraga učinjena je tek nakon postoperativnog pogoršanja. CT je potvrdio ultrazvučni nalaz mezenterijalnog limfangioma. Naknadno učinjen MR je najkvalitetnije prikazao karakteristike i lokalizaciju limfangioma te odnos prema susjednim strukturama. Stoga je MR slikovna metoda izbora u preoperativnoj obradi pacijenata $s$ intraabdominalnim limfangiomom ${ }^{13-14}$.

Terapijska metoda izbora je kompletna kirurška resekcija ${ }^{18}$. Prognoza je u slučaju kompletnog odstranjenja tumora izvrsna ${ }^{17}$. Opisano je liječenje retroperitonealnog limfangioma s visokim rizi- kom kirurške resekcije intracističnom aplikacijom sklerozirajućeg sredstva OK-432. OK-432 potiče sekreciju faktora nekroze tumora (TNF, engl. tumor necrosis factor) koji ima ulogu u regresiji limfangioma ${ }^{19}$. Također je opisana lokalna primjena bleomicina koji djeluje tako da potiče blagu upalu endotela ${ }^{20}$. Naš pacijent uspješno je liječen kompletnom kirurškom resekcijom tvorbe.

Zbog nespecifične simptomatologije te odsustva karakterističnih kliničkih i laboratorijskih nalaza, postavljanje dijagnoze intraabdominalnog limfan-

lako je apendicitis najčešći razlog abdominalnog bola koji zahtijeva kiruršku intervenciju u djece školske dobi, ako izostaju klasični simptomi i znakovi treba bez odgađanja učiniti slikovne pretrage, počevši od ultrazvuka.

gioma, osobito retroperitonealnog, predstavlja izazov. lako limfangiomi mogu biti asimptomatski, ponekad su udruženi s ozbiljnim komplikacija$\mathrm{ma}^{3,5-6,9,17}$.

Prikazom našeg pacijenta ističemo važnost razmatranja limfangioma u diferencijalnoj dijagnozi akutnog abdomena u djece. Pravovremenim postavljanjem dijagnoze izbjegavaju se nepotrebni invazivni zahvati. U većini slučajeva dijagnozu je moguće postaviti na temelju ultrazvučne pretrage, a za bolju procjenu lezije od koristi je $\mathrm{MR}^{13-14,16}$. Definitivna dijagnoza se postavlja patohistološkom analizom tkiva tumora ${ }^{12,16}$. Prognoza je nakon kompletne kirurške resekcije izvrsna ${ }^{17}$.

\section{ZAKLJUČAK}

Intraabdominalni limfangiomi su rijetki benigni limfatični tumori koji mogu predstavljati dijagnostičke poteškoće. Prikazom pedijatrijskog pacijenta $s$ retroperitonealnim limfangiomom udruženog $s$ komplikacijama želimo istaknuti važnost podrobne anamneze, detaljnog kliničkog pregleda i slikovnih metoda u diferencijalnoj dijagnozi akutnog abdomena u djece. Pravovremeno postavljanje točne dijagnoze omogućuje odabir optimalnog liječenja i izvrsnu prognozu.

Izjava o sukobu interesa: autori izjavljuju da ne postoji sukob interesa. 


\section{LITERATURA}

1. Hassan $\mathrm{H}$, AbdElelah Aly K. Management of cystic lymphangioma: experience of two referral centers. Ann Pediatr Surg 2012;8:123-8.

2. Olivieri C, Nanni L, De Gaetano AM, Manganaro L, Pintus C. Complete Resolution of Retroperitoneal Lymphangioma with a Single Trial of OK-432 in an Infant. Pediatr Neonatol 2016;57:240-3.

3. Chih-Cheng L, Chen-Sheng H, Hsun-Chin C, Shih-Ming C, Chuen H. Intra-Abdominal Cystic Lymphangiomas in Infancy And Childhood. Chang Gung Med J 2004;27:509-14.

4. Fayad Aly H. Abdominal Cystic Lymphangioma in Children. Ann Pediatr Surg 2009;5:132-6.

5. Khmekhem R, Rahay H, Ghorbel S, Jlidi S, Douira W and Bellagha I. Abdominal Cystic Lymphangioma. About Seven Cases. SM J Pediatr Surg. 2016;2:1029.

6. Mesić M, Cigit I, Žganjer M, Čizmić A, Župančić B, Madžar Z. Cystic lymphangioma of jejunal mesentery mimicking acute appendicitis: Case report. Acta Clin Croat 2013;52:129-32.

7. Tseng YC, Lee MS, Chang YJ, Wu HP. Acute Abdomen in Pediatric Patients Admitted to the Pediatric Emergency Department. Pediatr Neonatol 2008;49:126-34.

8. Strouse PJ. Imaging and the Child with Abdominal Pain. Singapore Med J 2003;44:312-22.

9. Galifer RB, Pous JG, Juskiewenski S, Pasquie M, Gaubert J. Intro-abdominal cystic lymphangiomas in childhood. Prog Pediatr Surg 1978;11:173-238.

10. Mirza B, ljaz L, Saleem M, Sharif M, Sheikh A. Cystic Hygroma: An Overview. J Cutan Aesthet Surg 2010;3:139-44.

11. Bhavsar T, Saeed-Vafa D, Harbison S, Inniss S. Retroperitoneal cystic lymphangioma in an adult: A case report and review of the literature. World J Gastrointest Pathophysiol 2010;1:171-6.
12. Minocha PK, Roop L, Persad R. Cases of atypical lymphangiomas in children. Case Rep Pediatr [Internet] 2014;2014:626198. [cited 2018 Apr 23]. Available from: https://www.ncbi.nlm.nih.gov/pmc/articles/ PMC4195264/

13. Losanoff JE, Richman BW, El-Sherif A, Rider KD, Jones JW. Mesenteric cystic lymphangioma. J Am Coll Surg 2003;196:598-603.

14. Ghatak S, Ray S, Sanyal S, Sonar PK, Khamrui S, Basu K et al. An unusual cause of acute abdomen in adults: giant cystic lymphangioma of the pancreatic head. A clinical case and literature review. JOP 2011;12: 266-70.

15. Konen O, Rathaus V, Dlugy E, Freud E, Kessler A, Shapiro $\mathrm{M}$ et al. Childhood abdominal cystic lymphangioma. Pediatr Radiol 2002;32:88-94.

16. Prehal M, Hager J, Haeussler B, Mueller T, Maurer K, Rauchenzauner $\mathrm{M}$ et al. Intraabdominal Cystic Lymphangiomas in Children: A Single Center Experience. Int J Clin Pediatr 2014;3:89-93.

17. Talukdar S, Alagaratnam S, Sinha A, Thorn CC, Elton C. Giant cystic lymphangioma in childhood: a rare differential for the acute abdomen. BMJ Case Rep [Internet] 2011;2011:bcr0420114105. [cited 2018 Apr 23]. Available from: https://www.ncbi.nlm.nih.gov/pmc/articles/ PMC3132640/

18. Morger R, Bolliger B, Müller M. Abdominal lymphangioma in childhood. Padiatr Padol 1991;26:31-4.

19. Ogita S, Tsuto T, Nakamura K, Deguchi E, Iwai N. OK-432 therapy for lymphangioma in children: why and how does it work? J Pediatr Surg 1996;31:477-80.

20. Muir T, Kirsten M, Fourie P, Dippenaar N, Ionescu GO. Intralesional bleomycin injection (IBI) treatment for haemangiomas and congenital vascular malformations. Pediatr Surg Int 2004; 19:766-73. 